\title{
NGHIÊN CỨU TỶ LẸ PHỐI TRộN THÍCH HợP GIŨA CHITOSAN VÀ NISIN ĐỂ BẢO QUẢN CAM SAU THU HOẠCH Ở NHIỆT Độ THƯờNG
}

\author{
Trần Văn Chi ${ }^{1 *}$, Phạm Thị Tuyết Mai ${ }^{1}$, Ta Thị Luợng ${ }^{1,2}$, Luu Hồng Sơn ${ }^{l}$ \\ ${ }^{1}$ Truò̀ng Đại học Nông Lâm - Đại học Thái Nguyên \\ ${ }^{2}$ Đại học Queensland \\ Email: tranvanchi@tuaf.edu.vn
}

\section{Thông tin bài viết}

Ngày nhận bài:

27/5/2020

Ngày duyệt đăng:

$12 / 8 / 2020$

Tù khóa:

Chitosan; nisin; phối trộn;

\section{Tóm tắt}

Nghiên cứu này tập trung vào việc trộn chitosan và nisin theo các tỷ lệ khác nhau, nhằm mang lại kết quả tốt nhất cho việc bảo quản cam ở nhiệt độ phòng. Thực nghiệm cho thấy tỷ lệ phối trộn giữa chitosan và nisin lần lượt là $1,5 \%$ và $400 \mathrm{IU} / \mathrm{ml}$ bảo quản cam ở nhiệt độ phòng cho kết quả tốt nhất sau 8 tuần bảo quản, cụ thể: tỷ lệ hư hỏng là 26,67\%, tỷ lệ hao hụt khối lượng là 29,04\%. , tổng hàm lượng axit hữu cơ là $0,56 \%$ tổng chất khô, hàm lượng vitamin $\mathrm{C}$ còn lại là $29,43 \mathrm{mg} / 100 \mathrm{~g}$ tổng chất khô, hàm lượng chất khô hòa tan là $10,3 \mathrm{oBx}$

quả cam; sau thu hoạch.

\section{MỞ ĐẦU}

Trong những năm gần đây, sản lượng cam của nước ta không ngừng được tăng lên. Tuy nhiên, bảo quản cam sau thu hoạch vẫn đang là một vấn đề cần giải quyết cho các nhà vườn cũng như các công ty chế biến. Vì sản lượng cam chỉ tập trung cao vào chính vụ, mà yêu cầu đảm bảo nguyên liệu ổn định trên thị trường trong thời gian dài, hơn nữa khó khăn hiện tại là quả cam sau khi thu hoạch có tỷ lệ hư hỏng cao [1]. Để khắc phục tình trạng này, hiện nay đã có nhiều phương pháp bảo quản được áp dụng nhằm kéo dài thời gian bảo quản cam như bảo quản bằng bao bì plastic, bằng bao bì ăn được và bằng bao bì sinh học chitosan $[2,11]$. Trong các chế phẩm tạo màng hiện nay, chế phẩm chitosan vẫn đang rất được quan tâm vì có tính kháng khuẩn, có khả năng tự phân hủy sinh học, dễ tương thích, có nguồn gốc tự nhiên, an toàn với người và vật nuôi, dễ sử dụng để làm chất bảo quản quả tươi...[ $[3,4,5]$.
Nisin là một loại bacterioxin được tổng hợp bởi vi khuẩn lactic [8], là một peptide kỵ nước gồm 34 axit amin trong đó có một axit amin đã cải biến, có khối lượng phân tử 3488 Dalton [13]. Nisin được xem là chất bảo quản thực phẩm chống thối hỏng có tiềm năng vì chúng có khả năng ức chế sự phát triển của nhiều loại vi khuẩn gây thối hỏng rau củ quả và gây bệnh ở người $[6,7]$. Ngoài ra, nisin còn có nhiều ưu điểm khác như phạm vi ứng dụng khá rộng bao gồm các sản phẩm tươi sống như thịt, cá, sữa, rau quả, các thực phẩm lên men, đồ hộp...[8]. Tuy nhiên, nisin không có khả năng tạo màng và dịch nisin lưu lại trên thực phẩm chỉ trong thời gian ngắn. Từ những đặc điểm trên cần phải có hướng giải quyết để có thể cố định được nisin giúp thời gian lưu lại lâu hơn, tăng được thời gian bảo quản cho sản phẩm. Đây là định hướng của nghiên cứu này, đó là sử dụng chitosan làm vật liệu màng cố định nisin thành một loại màng hỗn hợp sử dụng trong bảo quản quả cam sau thu hoạch. 


\section{VẬT LIỆU VÀ PHƯƠNG PHÁP NGHIÊN CÚ'U}

\section{Vật liệu nghiên cứu}

Quả cam Sành được thu hái đúng độ chín tại vườn trồng cam ở huyện Hàm Yên tỉnh Tuyên Quang. Quả cam sau khi thu hoạch được rửa dưới vòi nước sạch, để khô tự nhiên, bôi vôi vào cuống, dùng chổi sơn quét đều chế phẩm đã pha ở các nồng độ như trong phần bố trí thí nghiệm lên bề mặt quả và để khô tự nhiên. Sau đó, quả cam được xếp vào thùng carton và bảo quản ở nhiệt độ thường.

Chế phẩm nisin được cung cấp bởi hãng Sigma Mỹ đạt tiêu chuẩn Việt Nam 10637:2015 - có hoạt độ 900 IU. 1 đơn vị hoạt độ IU tương đương với 0,025 $\mu \mathrm{g}$ nisin. Tiến hành pha loãng theo nồng độ yêu cầu của thí nghiệm để đạt 200; 300; 400 và $500 \mathrm{IU} / \mathrm{ml}$. Chế phẩm chitosan cung cấp bởi hàng Sigma, Mỹ. Các hóa chất thông dụng trong phòng thí nghiệm như: $\mathrm{HCl}$, $\mathrm{CH}_{3} \mathrm{COOH}, \mathrm{NaOH}$, Phenolphtalein, Tinh bột, $\mathrm{I}_{2}$ được cung cấp bởi hàng Himedia, Ân Độ.

\section{Bố trí thí nghiệm}

Từ kết quả nghiên cứu của các tác giả trước đây [9], [10], [11] bảo quản cam và bưởi cho ra nồng độ chitosan tối thích là $1,5 \%$. Thí nghiệm này được tiến hành cố định nồng độ chitosan là $1,5 \%$, thay đổi nồng độ nisin theo 6 công thức, mỗi công thức sử dụng 20 quả cam có kích thước và khối lượng tương đương nhau, thí nghiệm được lặp lại 3 lần:

- Đối chứng 1 (ĐC1): không xử lý chitosan và nisin

- Đối chứng 2 (ĐC2): chitosan 1,5\%

- Công thức 1 (CT1): chitosan 1,5\% + nisin $200 \mathrm{IU} / \mathrm{ml}$

- Công thức 2 (CT2): chitosan 1,5\% + nisin $300 \mathrm{IU} / \mathrm{ml}$

- Công thức 3 (CT3): chitosan 1,5\% + nisin $400 \mathrm{IU} / \mathrm{ml}$

- Công thức 4 (CT4): chitosan 1,5\% + nisin $500 \mathrm{IU} / \mathrm{ml}$

Sau khi xử lý chế phẩm chitosan - nisin, cam được bảo quản ở nhiệt độ phòng, với các chỉ tiêu theo dõi: tỷ lệ hư hỏng, hao hụt khối lượng, hàm lượng vitamin $\mathrm{C}$, axit hữu cơ tổng số, chất hòa tan.

\section{Phương pháp phân tích}

Phưong pháp xác định tỷ lệ hu hỏng

Theo dõi theo ngày đếm và loại bỏ các quả hư hỏng.

Công thức tính tỷ lệ hư hỏng:

$$
\mathrm{X}=\frac{C}{A} \cdot 100(\%)
$$

Trong đó: X: Tỷ lệ hư hỏng (\%)

C: Số quả bị hư hỏng;

A: Tổng số lượng quả ban đầu

Phương pháp xác định tỷ lệ hao hụt khối luợng

- Cách xác định: Hao hụt khối lượng của cam được xác định bằng phương pháp cân khối lượng của mẫu trước khi bảo quản và sau mỗi lần kiểm tra định kỳ 1 tuần/lần.

- Công thức tính:

$$
\mathrm{X}=\frac{M 1-M 2}{M 1} \cdot 100(\%)
$$

Trong đó: X: Tỷ lệ hao hụt khối lượng (\%)

$\mathrm{M}_{1}$ : Khối lượng mẫu trước khi bảo quản

$\mathrm{M}_{2}$ : Khối lượng mẫu không bị hư hỏng sau mỗi thời kỳ theo dõi

Phuoong pháp xác định hàm lương vitamin C (mg) lo0g) [12]

Nguyên tắc: Dựa vào lượng iốt bị khử bởi vitamin $\mathrm{C}$ có trong mẫu sẽ tính ra được lượng vitamin $\mathrm{C}$ có trong nguyên liệu.

Tiến hành:

Cho vào cối sứ $10 \mathrm{~g}$ thịt quả (quả sau khi lấy ra làm thí nghiệm không được tính là quả bị hư hỏng hay hao hụt) và $20 \mathrm{ml} \mathrm{HCl} 5 \%$ nghiền nhỏ cho đến khi dung dịch có dạng đồng nhất, dùng nước cất để chuyển toàn bộ dịch chiết vào trong bình định mức $100 \mathrm{ml}$, thêm nước cất lên thể tích đến vạch.

Đặt bình định mức trong bóng tối khoảng 10 phút cho lượng vitamin $\mathrm{C}$ trong nguyên liệu được hòa tan hoàn toàn, sau đó bỏ ra lọc bằng giấy lọc.

Hút $30 \mathrm{ml}$ dịch lọc trong cho vào bình tam giác thể tích $100 \mathrm{ml}$. Thêm vào $5-10$ giọt hồ tinh bột $1 \%$ lắc nhẹ.

Dùng $\mathrm{I}_{2} 0,01 \mathrm{~N}$ chuẩn độ cho đến khi dung dịch xuất hiện màu xanh lam nhạt là được. Lặp lại chuẩn độ 3 lần, lấy kết quả trung bình [12].

Hàm lượng Vitamin $\mathrm{C}$ được tính theo công thức:

$$
\mathrm{X}=\frac{a \cdot V \cdot 0,00088 \cdot 1000}{v \cdot c} .1000
$$


Trong đó: $\mathrm{X}$ : hàm lượng vitamin $\mathrm{C}$ có trong nguyên liệu $(\mathrm{mg} / 100 \mathrm{~g})$

a: Số ml iốt $0,01 \mathrm{~N}$ dùng để chuẩn độ

v: Số ml dung dịch mẫu đi /phân tích

$\mathrm{V}$ : Thể tích của toàn bộ dịch chiết $(\mathrm{ml})$

c: Khối lượng nguyên liệu đem phân tích (g)

0,00088: số gam vitamin $\mathrm{C}$ tương ứng với $1 \mathrm{ml}$ iốt $0,01 \mathrm{~N} 1000$ ở tử là hệ số chuyển đổi $\mathrm{g}$ sang mg.

Phuơng pháp xác định hàm lương axít hũu co tổng số [12]

- Nguyên tắc: Trung hòa bằng $\mathrm{NaOH} 0,1 \mathrm{~N}$ với phenolphtalein $1 \%$ trong cồn làm chỉ thị màu.

- Tiến hành:

Nghiền nhỏ $5 \mathrm{~g}$ mẫu trong cối sứ cho đến khi dung dịch có dạng đồng thể, sau đó chuyển sang bình tam giác $250 \mathrm{ml}$ và thêm nước cất đến thể tích dung dịch là $150 \mathrm{ml}$. Đun cách thủy dung dịch trong 30 phút ở nhiệt độ $80-90^{\circ} \mathrm{C}$ và lắc đều sau mỗi 1 phút. Khi dung dịch đã nguội, lọc qua giấy lọc vào bình định mức, bổ sung nước cất đến $250 \mathrm{ml}$.

Lấy $50 \mathrm{ml}$ dịch lọc cho vào bình tam giác, cho thêm vào đó 1 - 2 giọt phenolphtalein rồi chuẩn độ bằng $\mathrm{NaOH} 0,1 \mathrm{~N}$ cho tới khi xuất hiện màu phớt hồng.

- Hàm lượng acid hữu cơ tổng số được tính theo công thức:

$$
\mathrm{X}=\frac{a \cdot 0,0067 \cdot T \cdot V}{v \cdot c} \cdot 100
$$

Trong đó: $\mathrm{a}$ Số $\mathrm{ml} \mathrm{NaOH} 0,1 \mathrm{~N}$ cần để chuẩn độ

0,0067: Số gam acid tương ứng với $1 \mathrm{ml} \mathrm{NaOH} \mathrm{0,1 \textrm {N }}$

T: Hệ số điều chỉnh đối với $\mathrm{NaOH} 0,1 \mathrm{~N}$

$\mathrm{V}$ : Tổng thể tích dung dịch chiết

v: Số ml dung dịch lấy để chuẩn độ c: Khối lượng mẫu (g)

100: Hệ số để tính $X$ theo g/100ml

Phuoong pháp xác định hàm lương chất hòa tan $\left({ }^{\circ} \mathrm{Bx}\right)$

Lấy 10 gam mẫu nghiền, sau đó nhỏ 1-2 giọt dung dịch lên trên bề mặt kính của máy chiết quang kế, sau đó đậy mặt kính lên.

Đọc chỉ số bằng cách: lấy giá trị tính từ vạch chỉ điểm số 0 tới điểm xanh cuối cùng trên thước số. Thí nghiệm được lặp lại 3 lần [14].

Phưong pháp xủ lý số liệu

Kết quả thí nghiệm được xử lý trên phần mềm SPSS 16.0.

\section{KẾT QUẢ VÀ THẢO LUẬN}

Ảnh hưởng của tỷ lệ phối trộn chitosan - nisin đến tỷ lệ hư hỏng của quả cam trong quá trình bảo quản

Trong công tác bảo quản, tỷ lệ thối hỏng là một trong những vần đề cần được quan tâm, bởi vì tỷ lệ thối hỏng sẽ ảnh hưởng trực tiếp đến hiệu quả bảo quản và giá trị kinh tế của quả sau thu hoạch. Hiệu quả bảo quản và tỷ lệ thối hỏng thấp sẽ mang lại hiệu quả kinh tế cao hơn. Theo dõi tỷ lệ thối hỏng trong quá trình bảo quản cam Sành Hàm Yên ở các tỷ lệ phối trộn khác nhau giữa Nisin và Chitosan được trình bày tại bảng 1 .

Mặc dù đã bị tách rời khỏi cây, quả cam vẫn tiếp tục xảy ra các hoạt động trao đổi chất và duy trì các quá trình sinh lý sinh hóa. Tuy nhiên, các biến đổi sau thu hoạch khác với các biến đổi trong quá trình phát triển, quá trình phát triển là sự thu nhận chất dinh dưỡng từ môi trường để tổng hợp thành các chất dự trữ, ngược lại các biến đổi sau thu hoạch là sự phân hủy và tiêu hao vật chất để sinh năng lượng duy trì quá trình sống của quả, các quá trình này làm cho quả biến đổi về khối lượng, màu sắc, mùi vị, độ axít, hàm lượng đường...[12]

Bảng 1: Ảnh hưởng của tỷ lệ phối trộn chitosan - nisin đến tỷ lệ hư hỏng của quả cam trong quá trình bảo quản

\begin{tabular}{|c|c|c|c|c|c|}
\hline \multirow{2}{*}{ Công thức } & \multicolumn{5}{|c|}{ Tỷ lệ hư hỏng (\%) } \\
\cline { 2 - 6 } & 2 tuần & 4 tuần & $\mathbf{6}$ tuần & $\mathbf{8}$ tuần & $\mathbf{1 0}$ tuần \\
\hline ĐC1 & $23,33^{\mathrm{a}}$ & $56,67^{\mathrm{a}}$ & $73,33^{\mathrm{a}}$ & $100,00^{\mathrm{a}}$ & - \\
\hline ĐC2 & $10,00^{\mathrm{b}}$ & $20,00^{\mathrm{b}}$ & $23,33^{\mathrm{b}}$ & $46,67^{\mathrm{b}}$ & $76,67^{\mathrm{b}}$ \\
\hline $\mathrm{CT} 1$ & $5,00^{\mathrm{bc}}$ & $13,33^{\mathrm{c}}$ & $15,00^{\mathrm{c}}$ & $31,67^{\mathrm{c}}$ & $53,33^{\mathrm{c}}$ \\
\hline $\mathrm{CT} 2$ & $6,67^{\mathrm{bc}}$ & $11,67^{\mathrm{c}}$ & $13,33^{\mathrm{c}}$ & $30,00^{\mathrm{cd}}$ & $50,00^{\mathrm{cd}}$ \\
\hline
\end{tabular}




\begin{tabular}{|c|c|c|c|c|c|}
\hline \multirow{2}{*}{ Công thức } & \multicolumn{5}{|c|}{ Tỷ lệ hư hỏng (\%) } \\
\cline { 2 - 6 } & $\mathbf{2}$ tuần & $\mathbf{4}$ tuần & $\mathbf{6}$ tuần & $\mathbf{8}$ tuần & $\mathbf{1 0}$ tuần \\
\hline CT3 & $3,33^{\mathrm{c}}$ & $8,33^{\text {cd }}$ & $11,67^{\mathrm{cd}}$ & $26,67^{\mathrm{d}}$ & $46,67^{\mathrm{d}}$ \\
\hline CT4 & $1,67^{\mathrm{c}}$ & $5,00^{\mathrm{d}}$ & $8,33^{\mathrm{d}}$ & $26,71^{\mathrm{d}}$ & $46,68^{\mathrm{d}}$ \\
\hline
\end{tabular}

(Trong cùng một cột các giá trị trung bình có số mũ khác nhau thì khác nhau có ý nghĩa ở mức $\alpha=0,05$ )

Qua bảng 1 ta thấy, có sự khác biệt rõ rệt về kết quả giữa các công thức bảo quản. Cụ thể mẫu $Đ C 1$ tỷ lệ hư hỏng tăng rất nhanh, sau 8 tuần cam bị hỏng $100 \%$. Sau 4 tuần các mẫu sử dụng phối trộn chitosan - nisin có sự khác biệt rõ rệt so với mẫu ĐC2 chỉ sử dung chitosan $1,5 \%$, tỷ lệ hư hỏng ít nhất ở CT4 và tăng dần CT3, CT2, CT1.

Sau 10 tuần, do thời gian bảo quản dài nên tỷ lệ hư hỏng khá lớn: 46,68\% (CT4); 46,67\% (CT3); 50\% (CT2); 55,33\% (CT1) và 76,67\% (ĐC2). Tuy nhiên, sự khác biệt về kết quả xử lý số liệu cho thấy CT3 và CT4 sai khác không có ý nghĩa. Ở các công thức còn lại kết quả hư hỏng là có sự khác biệt có ý nghĩa. Tỷ lệ hư hỏng giảm dần theo tỷ lệ tăng lên của nisin vì chitosan vừa có khả năng tạo màng vừa có khả năng kháng khuẩn kết hợp với nisin đã làm tăng khả năng kháng khuẩn giúp hạn chế quá trình hô hấp của quả, hạn chế quá trình phát triển của vi sinh vật gây hại trên vỏ quả,... giúp bảo quản cam tốt hơn. Lượng nisin bổ sung khi vượt quá $400 \mathrm{IU} / \mathrm{ml}$ không có sự khác biệt ở ngưỡng $400 \mathrm{IU} / \mathrm{ml}$ vì đến nồng độ đó khả năng cố định nisin của chitosan đã đạt trạng thái bão hòa ổn định. Vậy bảo quản có ý nghĩa là sau 8 tuần với CT3 cho kết quả tốt nhất.

Ảnh hưởng của tỷ lệ phối trộn chitosan - nisin đến hao hụt khối luọng của cam trong quá trình bảo quản

Sự hao hụt khối lượng tự nhiên của rau quả là vấn đề không thể tránh khỏi trong quá trình bảo quản, nếu bảo quản tốt sẽ giảm thiểu được sự hao hụt tự nhiên của quả và ngược lại, chính vì vậy để nâng cao được chất lượng hoa quả thì phải tìm ra những phương pháp bảo quản tốt nhất để giảm thiểu tối đa sự hao hụt khối lượng tự nhiên của quả.

Hàm lượng nước trong quả cam rất cao, trong vỏ là $74,7 \%$, trong múi tới $87,2 \%$. Khi còn ở trên cây, lượng nước bốc hơi được bù đắp thường xuyên nhờ sự hấp thu nước từ rễ cây.

Vì vậy sự mất nước của nông sản tươi sau thu hoạch có ảnh hưởng rất lớn đến trạng thái sinh lý cũng như chất lượng, khối lượng của quả [2].

Bảng 2: Ảnh hưởng của tỷ lệ phối trộn Chitosan - nisin đến hao hụt trọng lượng của cam trong quá trình bảo quản ở nhiệt độ thường

\begin{tabular}{|c|c|c|c|c|c|}
\hline \multirow{2}{*}{ Công thức } & \multicolumn{5}{|c|}{ Tỷ lệ hao hụt khối lượng (\%) } \\
\cline { 2 - 6 } & $\mathbf{2}$ tuần & $\mathbf{4}$ tuần & $\mathbf{6}$ tuần & $\mathbf{8}$ tuần & $\mathbf{1 0}$ tuần \\
\hline ĐC1 & $26,28^{\mathrm{a}}$ & $59,57^{\mathrm{a}}$ & $75,56^{\mathrm{a}}$ & $100,00^{\mathrm{a}}$ & $100,00^{\mathrm{a}}$ \\
\hline ĐC2 & $12,56^{\mathrm{b}}$ & $24,44^{\mathrm{b}}$ & $28,62^{\mathrm{b}}$ & $51,79^{\mathrm{b}}$ & $79,94^{\mathrm{b}}$ \\
\hline CT1 & $7,18^{\mathrm{bc}}$ & $16,74^{\mathrm{c}}$ & $19,23^{\mathrm{c}}$ & $35,63^{\mathrm{c}}$ & $56,58^{\mathrm{c}}$ \\
\hline CT2 & $8,81^{\mathrm{bc}}$ & $14,98^{\mathrm{c}}$ & $17,66^{\mathrm{c}}$ & $34,36^{\mathrm{cd}}$ & $53,95^{\mathrm{cd}}$ \\
\hline CT3 & $5,44^{\mathrm{c}}$ & $11,60^{\mathrm{d}}$ & $15,87^{\mathrm{d}}$ & $29,04^{\mathrm{d}}$ & $50,88^{\mathrm{d}}$ \\
\hline CT4 & $3,85^{\mathrm{c}}$ & $11,59^{\mathrm{d}}$ & $15,85^{\mathrm{c}}$ & $29,05^{\mathrm{d}}$ & $50,89^{\mathrm{c}}$ \\
\hline
\end{tabular}

(Trong cùng một cột các giá trị trung bình có số mũ khác nhau thì khác nhau có ý nghĩa ở mức $\alpha=0,05$ )

Qua số liệu bảng 2 cho thấy, tỷ lệ hao hụt khối lượng tăng dần trong quá trình bảo quản. Sau 10 tuần bảo quản, tỷ lệ hao hụt khối lượng cao nhất ở công thức ĐC1 - không được xử lý, với các công thức khác, tỷ lệ hao hụt khối lượng tương ứng ĐC2 (79,94\%), giảm dần ở CT1 (56,58\%), CT2 (53,95\%), CT3 $(50,88 \%)$ và CT4 $(50,89 \%)$. Như vậy tỷ lệ phối trộn chitosan - nisin có ảnh hưởng khá lớn đến tỷ lệ hao hụt khối lượng của quả cam trong quá trình bảo quản, 
và CT3 là công thức cho kết quả tối ưu để có thể áp dụng vào quy mô bảo quản quy mô lớn.

Ảnh hưởng của tỷ lệ phối trộn chitosan - nisin đến hàm lựng acid hũu cơ của quả cam trong quá trình bảo quản

Bảng 3: Ảnh hưởng của tỷ lệ phối trộn chitosan - nisin đến hàm lượng acid hữu cơ của quả cam trong quá trình bảo quản

\begin{tabular}{|c|c|c|c|c|c|c|}
\hline \multirow{2}{*}{ Công thức } & \multicolumn{5}{|c|}{ Hàm lượng acid hữu cơ tổng số (g/ 100 ml) sau ...(tuần) } \\
\cline { 2 - 7 } & Ban đầu & $\mathbf{2}$ tuần & $\mathbf{4}$ tuần & $\mathbf{6}$ tuần & $\mathbf{8}$ tuần & $\mathbf{1 0}$ tuần \\
\hline $\mathrm{ÐC} 1$ & 0,70 & $0,47^{\mathrm{d}}$ & $0,44^{\mathrm{d}}$ & $0,43^{\mathrm{d}}$ & - & - \\
\hline $\mathrm{DC} 2$ & 0,70 & $0,57^{\mathrm{c}}$ & $0,51^{\mathrm{c}}$ & $0,49^{\mathrm{c}}$ & $0,46^{\mathrm{c}}$ & $0,44^{\mathrm{c}}$ \\
\hline $\mathrm{CT} 1$ & 0,70 & $0,61^{\mathrm{b}}$ & $0,57^{\mathrm{b}}$ & $0,56^{\mathrm{b}}$ & $0,54^{\mathrm{b}}$ & $0,53^{\mathrm{b}}$ \\
\hline $\mathrm{CT} 2$ & 0,70 & $0,61^{\mathrm{b}}$ & $0,56^{\mathrm{b}}$ & $0,56^{\mathrm{b}}$ & $0,54^{\mathrm{b}}$ & $0,53^{\mathrm{b}}$ \\
\hline $\mathrm{CT} 3$ & 0,70 & $0,61^{\mathrm{b}}$ & $0,57^{\mathrm{b}}$ & $0,57^{\mathrm{a}}$ & $0,56^{\mathrm{a}}$ & $0,54^{\mathrm{a}}$ \\
\hline $\mathrm{CT} 4$ & 0,70 & $0,62^{\mathrm{a}}$ & $0,58^{\mathrm{a}}$ & $0,57^{\mathrm{a}}$ & $0,56^{\mathrm{a}}$ & $0,54^{\mathrm{a}}$ \\
\hline
\end{tabular}

(Trong cùng một cột các giá trị trung bình có số mũ khác nhau thì khác nhau có ý nghĩa ở mức $\alpha=0,05$ )

Qua kết quả bảng 3 cho thấy, hàm lượng axit hữu cơ giảm dần trong quá trình bảo quản, cụ thể trong 2 tuần đầu hàm lượng axit hữu cơ giảm mạnh nhất, giai đoạn sau giảm không đáng kể. Các mẫu sử dụng chế phẩm có hàm lượng axit hữu cơ giảm ít hơn do hạn chế được quá trình hô hấp của quả. Sau 10 tuần hàm lượng axit hữu cơ còn lại ở CT1, CT2, CT3, CT4 lần lượt là 0,$53 ; 0,53 ; 0,54$ và $0,54 \%$ trong khi đó mẫu ĐC2 là $0,44 \%$. Sự khác nhau này có thể giải thích do khi sử dụng chế phẩm phối trộn chitosan - nisin giúp ức chế sự phát triển của vi sinh vật trên quả do vậy hạn chế sự hô hấp của vi sinh vật, cho nên cũng hạn chế sự sinh nhiệt, giúp hạn chế quá trình hô hấp của quả làm cho hàm lượng axit hữu cơ thay đổi ít hơn. Sau 10 tuần bảo quản hàm lượng axit hữu cơ còn lại cao nhất ở CT4. Tuy nhiên, theo kết quả xử lý số liệu sự khác biệt là không có ý nghĩa với kết quả của CT3.
Do vậy, sử dụng CT3 trong bảo quản sẽ tiết kiệm được chi phí.

Anh hưởng của tỷ lệ phối trộn chitosan - nisin đến hàm luọng vitamin $C$ của cam trong quá trình bảo quản ở nhiệt độ thuờng

Cam là loại quả có giá trị dinh dưỡng cao, chứa nhiều thành phần dinh dưỡng cần thiết cho cơ thể, đặc biệt là vitamin $\mathrm{C}(45 \mathrm{mg} / 100 \mathrm{~g})$, các loại đường, các loại khoáng ..., sau khi thu hoạch hàm lượng vitamin, nhất là vitamin $\mathrm{C}$ sẽ nhanh chóng bị phân hủy [1]. Vì vậy, vitamin $\mathrm{C}$ là một trong những chỉ tiêu hóa sinh quan trọng để đánh giá chất lượng quả cam sau thu hoạch. Hàm lượng vitamin $\mathrm{C}$ của cam Sành Hàm Yên tương đối cao và giảm dần theo thời gian bảo quản. Phương pháp bảo quản tốt sẽ hạn chế thấp nhất sự giảm hàm lượng vitamin $\mathrm{C}$. Để xác định được hàm lượng vitamin $C$ của cam Sành Hàm Yên những thí nghiệm theo dõi được trình bày tại bảng 4 .

Bảng 4: Ảnh hưởng của tỷ lệ phối trộn chitosan - nisin đến hàm lượng vitamin $\mathrm{C}$ của quả cam trong quá trình bảo quản

\begin{tabular}{|c|c|c|c|c|c|c|}
\hline \multirow{2}{*}{ Công thức } & \multicolumn{5}{|c|}{ Hàm lượng vitamin C (mg/ 100g) sau ...(tuần) } \\
\cline { 2 - 7 } & Ban đầu & $\mathbf{2}$ tuần & $\mathbf{4}$ tuần & $\mathbf{6}$ tuần & $\mathbf{8}$ tuần & $\mathbf{1 0}$ tuần \\
\hline ĐC1 & 41,57 & $29,33^{\mathrm{d}}$ & $25,23^{\mathrm{d}}$ & $24,053^{\mathrm{d}}$ & - & - \\
\hline ĐC2 & 41,57 & $32,66^{\mathrm{c}}$ & $30,51^{\mathrm{c}}$ & $29,04^{\mathrm{c}}$ & $26,40^{\mathrm{c}}$ & $24,05^{\mathrm{c}}$ \\
\hline $\mathrm{CT} 1$ & 41,57 & $34,71^{\mathrm{b}}$ & $32,36^{\mathrm{b}}$ & $31,48^{\mathrm{b}}$ & $28,57^{\mathrm{b}}$ & $25,42^{\mathrm{b}}$ \\
\hline $\mathrm{CT} 2$ & 41,57 & $34,52^{\mathrm{b}}$ & $32,46^{\mathrm{b}}$ & $31,68^{\mathrm{b}}$ & $28,63^{\mathrm{b}}$ & $25,42^{\mathrm{b}}$ \\
\hline CT3 & 41,57 & $34,71^{\mathrm{b}}$ & $32,56^{\mathrm{b}}$ & $31,58^{\mathrm{b}}$ & $29,43^{\mathrm{a}}$ & $26,98^{\mathrm{a}}$ \\
\hline CT4 & 41,57 & $35,39^{\mathrm{a}}$ & $33,34^{\mathrm{a}}$ & $32,75^{\mathrm{a}}$ & $29,43^{\mathrm{a}}$ & $26,98^{\mathrm{a}}$ \\
\hline
\end{tabular}


(Trong cùng một cột các giá trị trung bình có số mũ khác nhau thì khác nhau có ý nghĩa ở mức $\alpha=0,05$ )

Qua bảng 4 cho thấy, hàm lượng vitamin $\mathrm{C}$ giảm dần trong thời gian bảo quản. Trong 2 tuần đầu hàm lượng vitamin $\mathrm{C}$ giảm mạnh nhất, có thể giải thích do sự thay đổi môi trường sống đột ngột nên quả có những rối loạn sinh lý sinh hóa, làm tăng cường độ hô hấp dẫn đến tiêu hao nhiều acid hữu cơ trong đó có acid ascorbic. Sau 2 tuần hàm lượng vitamin $\mathrm{C}$ giảm ít nhất ở CT4 (giảm 6,17 mg/ 100g), giảm mạnh nhất ở mẫu ĐC (giảm 12,23mg/ 100g).
Sau 10 tuần, hàm lượng vitamin $\mathrm{C}$ ở $\mathrm{CT} 4$ là cao nhất $(26,98 \mathrm{mg} / 100 \mathrm{~g})$, giảm dần ở CT3 (26,98mg/ $100 \mathrm{~g})$, CT2 (25,42 mg/ 100g), CT1 (25,42 mg/ 100g) và cuối cùng ĐC2 $(24,05 \mathrm{mg} / 100 \mathrm{~g})$. Tuy nhiên, kết quả tỷ lệ thay đổi của hàm lượng vitamin $\mathrm{C}$ ở $\mathrm{CT} 3$ và CT4 sai khác không có ý nghĩa. Vậy để đảm bảo tiết kiệm chi phí CT3 được khuyến cáo lựa chọn để thực hiện trong sản xuất.

\section{Ảnh huởng của tỷ lệ phối trộn chitosan - nisin đến hàm lựng chất hòa tan của quả cam trong quá trình bảo quản}

Bảng 5: Ảnh hưởng của tỷ lệ phối trộn chitosan - nisin đến hàm lượng chất hòa tan của quả cam trong quá trình bảo quản

\begin{tabular}{|c|c|c|c|c|c|c|}
\hline \multirow{2}{*}{ Công thức } & \multicolumn{6}{|c|}{ Chất khô hòa tan ( ${ }^{\mathbf{0}}$ Bx) sau... (tuần) } \\
\cline { 2 - 7 } & Ban đầu & $\mathbf{2}$ tuần & $\mathbf{4}$ tuần & $\mathbf{6}$ tuần & $\mathbf{8}$ tuần & $\mathbf{1 0}$ tuần \\
\hline ĐC1 & 9,67 & $11,33^{\mathrm{a}}$ & $11,67^{\mathrm{a}}$ & $11,80^{\mathrm{a}}$ & - & - \\
\hline ĐC2 & 9,67 & $9,93^{\mathrm{b}}$ & $10,23^{\mathrm{b}}$ & $10,27^{\mathrm{b}}$ & $10,50^{\mathrm{a}}$ & $10,67^{\mathrm{a}}$ \\
\hline $\mathrm{CT} 1$ & 9,67 & $9,90^{\mathrm{b}}$ & $10,13^{\mathrm{bc}}$ & $10,17^{\mathrm{c}}$ & $10,47^{\mathrm{a}}$ & $10,53^{\mathrm{b}}$ \\
\hline CT2 & 9,67 & $9,90^{\mathrm{b}}$ & $10,10^{\mathrm{c}}$ & $10,13^{\mathrm{c}}$ & $10,41^{\mathrm{b}}$ & $10,50^{\mathrm{b}}$ \\
\hline CT3 & 9,67 & $9,83^{\mathrm{b}}$ & $10,10^{\mathrm{c}}$ & $10,17^{\mathrm{c}}$ & $10,30^{\mathrm{c}}$ & $10,47^{\mathrm{b}}$ \\
\hline CT4 & 9,67 & $9,83^{\mathrm{b}}$ & $10,07^{\mathrm{c}}$ & $10,10^{\mathrm{c}}$ & $10,27^{\mathrm{c}}$ & $10,40^{\mathrm{b}}$ \\
\hline
\end{tabular}

(Trong cùng một cột các giá trị trung bình có số mũ khác nhau thì khác nhau có ý nghĩa ở mức $\alpha=0,05$ )

Hàm lượng chất hòa tan tổng số là một trong những chỉ tiêu đánh giá chất lượng của cam Sành Hàm Yên. Trong thời gian bảo quản, hàm lượng chất hoà tan có thể tăng hay giảm tuỳ thuộc vào điều kiện bảo quản. Hiện tượng tăng hàm lượng chất hoà tan tổng số (hay độ Brix) của các loại quả có múi nói chung và quả cam nói riêng do những nguyên nhân chính sau đây: Do sự thuỷ phân thành tế bào của nhiều loại enzim khác nhau như: Pectinaza, xenlulolaza, hemixenlulolaza và pectinesteraza làm chuyển hoá các chất không tan thành chất tan. Hàm lượng chất hòa tan tổng số của cam Sành Hàm Yên trong thời gian bảo quản được trình bày tại bảng 5 .

Kết quả bảng 5 cho thấy, hàm lượng chất hòa tan tăng dần theo thời gian bảo quản, tăng mạnh nhất là ở mẫu ĐC1, đối với các công thức sử dụng chế phẩm hàm lượng chất hòa tan tăng ít hơn. Sau 10 tuần, hàm lượng chất hòa tan tăng $0,73^{\circ} \mathrm{Bx}(\mathrm{CT} 4) ; 0,8^{\circ} \mathrm{Bx}(\mathrm{CT} 3)$; $0,83^{\circ} \mathrm{Bx}(\mathrm{CT} 2) ; 0,86^{\circ} \mathrm{Bx}(\mathrm{CT} 1)$ và $1,0^{\circ} \mathrm{Bx}(\mathrm{ÐC} 2)$.

\section{KẾT LUẬN}

Khi sử dụng dung dịch chitosan 1,5\% kết hợp với nisin $400 \mathrm{IU} / \mathrm{ml}$ để bảo quản cam Sành trồng tại huyện Hàm Yên, tỉnh Tuyên Quang cho kết quả tốt nhất so với các công thức khác. Sau 8 tuần bảo quản, tỷ lệ hư hỏng thấp $(26,67 \%)$; tỷ lệ hao hụt khối lượng là 29,04\%; hàm lượng vitamin $\mathrm{C}$ còn lại 29,43 mg/100g; hàm lượng acid hữu cơ tổng số đạt $0,56 \%$; hàm lượng chất hòa tan $10,3^{\circ} \mathrm{Bx}$ và chất lượng cảm quan tốt, vỏ quả bóng, màu vàng sáng, duy trì được độ cứng, quả còn nguyên cuống, vị ngọt, tép cam không bị nát hoặc khô. Do vậy có thể bảo quản cam đến 8 tuần trong điều kiện nhiệt độ thường, sử dụng tỷ lệ phối trộn giữa chitosan và nisin là $1,5 \%$ và $400 \mathrm{IU} / \mathrm{ml}$ sẽ cho kết quả bảo quản tốt.

\section{TÀI LIỆU THAM KHẢO}

1. Nguyen Huu Dang, Citrus fruits, Publisher: Agriculture, 2003.

2. Quach Dinh, Nguyen Van Tiep, Nguyen Van Thao, Technology after harvesting and processing vegetables. Publisher:Science and Technology , 1996. 
3. Huynh Nguyen Duy Bao, Tran Thi Luyen et al., Completing Chitin - Chitosan production process and processing some industrial products from shrimp and crab shell scrap. Scientific report (ministry level) Nha Trang, 2000.

4. Luu Van Chinh, Chau Van Minh, Pham Huu Dien, $\mathrm{Vu}$ Manh Hung, Ngo Thi Thuan, "Synthesize and research the blood cholesterol lowering effect of $\mathrm{N}, \mathrm{N}$, $\mathrm{N}$ - trimethy chitosan", Journal of Pharmacology, (No. 9), sec. 5, 2000.

5. Tran Thi Luyen, Le Thanh Long, "Research on preserving fresh chicken eggs with chitosan coated with additives", Journal of Fisheries Science and Technology, Nha Trang University, No. 1, p. $3-11$, 2007.

6. Do Thi Huyen, et al., "Research on production technology and use of biocides (nisin and enterocin) used in preserving agricultural products and foodstuffs". Synthesized report on scientific and technological results of scientific and technological topics at the state level, 2010.

7. Kykkidou S, Pournis N, Kostoula OK, Savvaidis IN, "Effects of treatment with nisin on the microbial flora and sensory properties of a Greek soft acid curd cheese stored aerobically at $4^{\circ} \mathrm{C}^{\prime \prime}$, Int Dairy $\mathrm{J}$, 17(10):1254 -1258, 2007

8. Nguyen La Anh. Research on technology to produce bacterioxin bio-preservative by microbiological method, which is applied in the food industry. Synthesized report on scientific and technological results on the topic of international cooperation tasks on science and technology according to protocol, 2010.

9. Tran Thi Hien. Application of chitosan-nano silver combination product in orange preservation. Graduate thesis. Agriculture and Forestry University - Thai Nguyen University, 2015.

10. Tran Thi Hai. Application of chitosan-nano silver combination in pomelos preservation. Graduate thesis. Agriculture and Forestry University - Thai Nguyen University, 2015.

11. Nguyen Duc Tuan, Ha Quang Viet, Ta Thi Mua. "Research on the effect of concentration of chitosan on quality and preservation time of Doan Hung grapefruit (Citrus grandis Osbeck)". Journal of Agriculture and Rural Development, November 2010, p. 80-83.

12. Ha Van Thuyet, Tran Quang Binh (2002), Preserving fresh fruits and vegetables and selling inoculants, Agricultural Publisher, 2002.

13. Delves-Broughton, J (1990), Nisin and it's uses as a food preservation, Food Technology, 100117.

14. Le Thanh Mai (2006), The analytical method of fermentation industry. Publisher: Science and Technology

\section{Study on the appropriate mixing ratio between chitosan and nisin to preserve post-harvest oranges at room temperate}

Tran Van Chi, Pham Thi Tuyet Mai, Ta Thi Luong, Luu Hong Son

\section{Article info}

Recieved:

27/5/2020

Accepted:

$12 / 8 / 2020$

Keywords:

Chitosan, mixing, nisin orange, presavation.

\begin{abstract}
This study focuses on mixing chitosan and nisin in different proportions, in order to give the best results for preserving oranges at room temperature. Experiments have shown that the mixing ratio between chitosan and nisin, respectively $1.5 \%$ and $400 \mathrm{IU} / \mathrm{ml}$, preserve oranges at room temperature for the best results after 8 weeks of storage, namely: spoilage rate is $26.67 \%$, weight loss ratio is $29.04 \%$, total organic acid content is $0.56 \%$ of total dry matter, remaining vitamin $\mathrm{C}$ content is $29.43 \mathrm{mg} / 100 \mathrm{~g}$ of total dry matter, soluble dry matter content is $10.3^{\circ} \mathrm{Bx}$
\end{abstract}

